Editorial

\title{
Polymeric Materials for Water and Wastewater Management
}

\author{
George Z. Kyzas *(D) and Athanasios C. Mitropoulos* \\ Department of Chemistry, International Hellenic University, 65404 Kavala, Greece \\ * Correspondence: kyzas@chem.ihu.gr (G.Z.K.); amitrop@chem.ihu.gr (A.C.M.); Tel.: +30-2510-466218 (G.Z.K.); \\ $+30-2510-462602$ (A.C.M.)
}

Citation: Kyzas, G.Z.; Mitropoulos A.C. Polymeric Materials for Water and Wastewater Management. Polymers 2021, 13, 168. https:// doi.org/10.3390/polym13010168

Received: 28 December 2020 Accepted: 31 December 2020 Published: 5 January 2021

Publisher's Note: MDPI stays neutral with regard to jurisdictional clai$\mathrm{ms}$ in published maps and institutional affiliations.

Copyright: (C) 2021 by the authors. Licensee MDPI, Basel, Switzerland. This article is an open access article distributed under the terms and conditions of the Creative Commons Attribution (CC BY) license (https:// creativecommons.org/licenses/by/ $4.0 /)$.
Water is a crucial point of interest nowadays due to its special management. At the same time, wastewater is one of the important pollution types in the water environment. The careful management of water and wastewater is a big challenge and a "hot" trend of recent research. During the last century, a huge amount of wastewater has been discharged into rivers, lakes, and coastal areas. This has resulted in serious pollution problems in aqueous environments. Therefore, it is mandatory to find an appropriate technique in order to efficiently treat and manage water and wastewater. Some indicative/typical methods are biological treatments, adsorption, flocculation, oxidation, membranes, and filtration. All of the above can be achieved by using polymeric materials (polymeric adsorbent materials, polymeric flocculants, polymeric filters, polymeric membranes, polymeric composites, etc.). This Special Issue on "Polymeric Materials for Water and Wastewater Management" sought high-quality works and topics focusing on (but not restricted to) the latest approaches to the management of water and wastewater including biological, chemical, adsorption, flocculation, oxidation, membranes, and filtration using polymeric materials.

This Special Issue on "Polymeric Materials for Water and Wastewater Management", we believe, succeeded to present such high-quality works and topics focusing on the latest novel wastewater processes using polymeric materials. This Special Issue consists of 11 works (9 research articles, 1 review paper, and 1 teaching note) from distinguished authors worldwide [1-11].

Basheer et al. investigated the use of hybrid carbon nanotubes (CNTs) (prepared by chemical vapor deposition (CVD)) to remove alumina [2], while Iqhrammullah et al. studied the synthesis and characterization of filler-modified castor-oil-based polyurethane foam as an adsorbent material to remove heavy metal ions [5]. Kluczka used, after synthesis, an innovative and environmentally friendly method for boron and manganese removalfrom flue gas desulfurization (FGD) wastewater-that is based on a hybrid chitosanzirconium hydrogel sorbent [6]. The efficient removal of $\mathrm{Pb}$ (II) from aqueous solutions by using oil palm biowaste/MWCNT-reinforced polyvinyl alcohol (PVA) hydrogel composites was presented by Zufiqar et al. in the Special Issue, and specifically, that study was focused on kinetics, isotherms, and thermodynamics [11]. In another study, Floros et al. focused on enhancing the flux on hydrophobic polymeric membranes aimed for the direct contact membrane distillation desalination (DCMD) process without compromising salt rejection efficiency [3]. Sun et al. investigated a novel system that was set up by preparing a magnetic flocculant combined with ultraviolet $/ \mathrm{H}_{2} \mathrm{O}_{2}$ to realize the rapid enrichment and degradation of diclofenac sodium (DCFS) [7]. Additionally, a composite chitosan/nanoactivated carbon (CS-NAC) aminated by (3-aminopropyl)triethoxysilane (APTES) was prepared in the form of beads by Vakili et al. and applied for the removal of acetaminophen from aqueous solutions [8]. Ahualli et al. studied an assembly of soft electrodes and ion exchange membranes for capacitive deionization [1]. Gkika et al. presented an interesting topic of cost estimation of various polymeric adsorbent materials used in literature for wastewater treatment [4], while a review by Yang et al. [10] provides insight into synthesis approaches and structural properties of recent reverse osmosis $(\mathrm{RO})$ and nanofiltration $(\mathrm{NF})$ 
membranes which are used to retain dissolved species such as heavy metals, electrolytes, and inorganic salts in various aqueous solutions. A specific focus of that article was placed on introducing and comparing the water purification performances of different classes of polymeric and ceramic membranes in related water-treatment industries. A technical report by Xia et al. demonstrated a strategy to design a modified starch/polyvinyl alcohol composite (CCSP) which was employed as a highly efficient and economical fixed-bed adsorbent for treating textile wastewater [9].

Many authors, whom we-as editors-thank very much, from various countries contributed marvellously to the present Special Issue. All the aforementioned topics and many more were explored in detail. Certainly, the field of wastewater treatment using polymeric materials and its processes is vast; the present study hopefully adds one more useful contribution.

Author Contributions: Writing—original draft preparation and supervision, writing—review and editing, and supervision, A.C.M. and G.Z.K. All authors have read and agreed to the published version of the manuscript.

Conflicts of Interest: The authors declare no conflict of interest.

\section{References}

1. Ahualli, S.; Orozco-Barrera, S.; Fernández, M.d.M.; Delgado, Á.V.; Iglesias, G.R. Assembly of Soft Electrodes and Ion Exchange Membranes for Capacitive Deionization. Polymers 2019, 11, 1556. [CrossRef] [PubMed]

2. Basheer, A.O.; Hanafiah, M.M.; Abdulhakim Alsaadi, M.; Wan Yaacob, W.Z.; Al-Douri, Y. Synthesis, Characterization, and Analysis of Hybrid Carbon Nanotubes by Chemical Vapor Deposition: Application for Aluminum Removal. Polymers 2020, 12, 1305, Erratum in 2020, 12, 1702. [CrossRef] [PubMed]

3. Floros, I.N.; Kouvelos, E.P.; Pilatos, G.I.; Hadjigeorgiou, E.P.; Gotzias, A.D.; Favvas, E.P.; Sapalidis, A.A. Enhancement of Flux Performance in PTFE Membranes for Direct Contact Membrane Distillation. Polymers 2020, 12, 345. [CrossRef] [PubMed]

4. Gkika, D.A.; Liakos, E.V.; Vordos, N.; Kontogoulidou, C.; Magafas, L.; Bikiaris, D.N.; Bandekas, D.V.; Mitropoulos, A.C.; Kyzas, G.Z. Cost Estimation of Polymeric Adsorbents. Polymers 2019, 11, 925. [CrossRef] [PubMed]

5. Iqhrammullah, M.; Hedwig, R.; Karnadi, I.; Kurniawan, K.H.; Olaiya, N.G.; Mohamad Haafiz, M.K.; Abdul Khalil, H.P.S.; Abdulmadjid, S.N. Filler-Modified Castor Oil-Based Polyurethane Foam for the Removal of Aqueous Heavy Metals Detected Using Laser-Induced Breakdown Spectroscopy (LIBS) Technique. Polymers 2020, 12, 903. [CrossRef] [PubMed]

6. Kluczka, J. Removal of Boron and Manganese Ions from Wet-Flue Gas Desulfurization Wastewater by Hybrid Chitosan-Zirconium Sorbent. Polymers 2020, 12, 635. [CrossRef] [PubMed]

7. Sun, Q.; Zheng, H.; Hu, X.; Li, J.; Zhao, R.; Zhao, C.; Ding, W. Magnetic Template Anion Polyacrylamide-Polydopamine-Fe ${ }_{3} \mathrm{O}_{4}$ Combined with Ultraviolet/H2O2 for the Rapid Enrichment and Degradation of Diclofenac Sodium from Aqueous Environment. Polymers 2020, 12, 72. [CrossRef] [PubMed]

8. Vakili, M.; Amouzgar, P.; Cagnetta, G.; Wang, B.; Guo, X.; Mojiri, A.; Zeimaran, E.; Salamatinia, B. Ultrasound-Assisted Preparation of Chitosan/Nano-Activated Carbon Composite Beads Aminated with (3-Aminopropyl)Triethoxysilane for Adsorption of Acetaminophen from Aqueous Solutions. Polymers 2019, 11, 1701. [CrossRef] [PubMed]

9. Xia, K.; Liu, X.; Wang, W.; Yang, X.; Zhang, X. Synthesis of Modified Starch/Polyvinyl Alcohol Composite for Treating Textile Wastewater. Polymers 2020, 12, 289. [CrossRef]

10. Yang, Z.; Zhou, Y.; Feng, Z.; Rui, X.; Zhang, T.; Zhang, Z. A Review on Reverse Osmosis and Nanofiltration Membranes for Water Purification. Polymers 2019, 11, 1252. [CrossRef] [PubMed]

11. Zulfiqar, M.; Lee, S.Y.; Mafize, A.A.; Kahar, N.A.M.A.; Johari, K.; Rabat, N.E. Efficient Removal of Pb(II) from Aqueous Solutions by Using Oil Palm Bio-Waste/MWCNTs Reinforced PVA Hydrogel Composites: Kinetic, Isotherm and Thermodynamic Modeling. Polymers 2020, 12, 430. [CrossRef] [PubMed] 